\title{
La nueva política migratoria en la Argentina: la tensión entre el "derecho de migrar" y los "imaginarios sociales" históricamente construidos
}

\author{
Tamajara Janaina Luiz da Silva*
}

\section{INTRODUCCIÓN}

Durante el trabajo etnográfico sobre las narrativas de los africanos solicitantes del estatuto de refugiado iniciado en el año de 2009 en la Argentina, pude observar ciertas tensiones desplegadas a partir de las acciones políticas cotidianas relativas a este reconocimiento ${ }^{1}$. Fue cuando pensé que las mismas podrían estar ligadas a diferentes "imaginarios sociales" construidos en torno de los refugiados y migrantes - dos actores históricamente entrelazados - al largo del tiempo. Este análisis condujo a una inmersión historiográfica acerca de las políticas del Estado y algunas observaciones en campo que hicieron posible evidenciar los puntos de vista de los actores institucionales durante el año de 2010 a 2012 en torno del tema. Allí pude entender que el dilema enfrentado por los funcionarios estatales sobre ser "autoridad" o "servidor público"2 (MIRANDA, 2005), estaban profundamente entretejido con la construcción de proyectos nacionales sobre migración y refugio, en especial, cuando se considera la especificidad de la población africana y los "imaginarios sociales" producto de los mismos. Estos proyectos del Estado no son abstractos, ya que son operados por un "cuerpos de agentes" que lo instituyen; aspecto crucial para comprender que cuando se habla de relaciones institucionales, en este texto, se refiere a personas que están sumergidas en ciertas estructuras sociales y no cosas.

\footnotetext{
* Licenciada en Ciencias Sociales por la Fundação Universidade Regional de Blumenau-Brasil, cursó Magister en Antropología Social en la Universidad Nacional de San Martín-Argentina. Actualmente es Doctoranda en Antropología Social en la Universidad Nacional de MisionesArgentina por intermedio de la Beca Doctoral del CONICET (Consejo Nacional de Investigaciones Científicas y Técnicas) y está cursando en la Fundación Henry Dunant-Chile la Especialización en Derechos Humanos y Políticas Públicas de Protección de Refugiados y Migración. CONICET/ PPAS-UNaM. E-mail: tamalogia@gmail.com
} 
Para percibir cómo se logró establecer una nueva política migratoria en la Argentina a pesar de "los imaginarios sociales" históricamente construidos en torno de los migrantes y los refugiado, busqué estar atenta en la manera que cada actor institucional fue posicionándose en el tiempo. En ese sentido, el aspecto histórico se tornó clave en la medida que analizaba el poder edificado por algunas instituciones que se tornaron protagonistas en la reestructuración de la nueva normativa jurídica migratória. Lo que observaba, era la continua relación de estos organismos con litigios nacionales e internacionales llamados de: casos paradigmáticos; procesos destacados no apenas por su singularidad, sino que, al lograren entrar en conflicto y replantear otro modus operandi sobre las prácticas desarrolladas por los agentes estatales.

De este modo, por un lado, percibía que el proceso de otorgamiento de refugio estaba atravesado por la producción de actividades y rutinas administrativas dinámicas, empleadas desde la armonización de las normativas jurídicas que fueron transformándose al largo del tiempo. Por otro lado, todavía parecía necesario analizar los acontecimientos históricos y los contornos de estas leyes, es decir, entender los "procesos que apuntalaban y moldeaban estos hechos", ese el objetivo de este trabajo. Para ello, me valgo de los aportes de Wolf (2001) cuando en su búsqueda por entender cómo operan las ideas y el poder en las relaciones sociales señala que las respuestas a sus preguntas exigió ir: "más allá del presente etnográfico" pues implicó situar su objeto de estudio en el tiempo.

Todavía cabe aclarar que no establecí nombres ficticios a las organizaciones de la sociedad civil (ONG's) pero hice lo posible para preservar sus nombres, puesto que se estará evidenciando "relaciones de poder", un tema delicado cuando se observa lo espinoso que fue conquistar una posición social en este campo y lo que podría representar perderla, en especial, para las ONG's. No obstante, en relación a los organismos estatales, entendí que la omisión de sus nombres comprometería la comprensión de este trabajo, aunque resguardé la identidad de sus agentes.

\section{LA MIGRACIÓN Y EL REFUGIO EN LAS EXPRESIONES HISTÓRICAS}

Al observar, desde la dimensión histórica, las políticas del Estado-nacional en relación al tema de la migración y refugio, se entiende que este "cuerpo de las costumbres" está sujetado por la "tradición" construida al largo del tiempo y de forma dinámica sobre el sujeto migrante y refugiado - definiciones que están históricamente entrelazadas. El análisis sobre el proyecto fundacional de la "Argentina moderna" luego de la Independencia (1810), revela la construcción de un ideal en que el migrante traería consigo un bagaje civilizatorio a partir del desarrollo económico y social para al país. Estas expectativas construidas desde las élites fueron acompañadas de un "cuerpo de leyes" que permitió poner en 
prácticas estas aspiraciones. Con Bernardino Rivadavia comienzan las primeras acciones institucionales para una política migratoria. En el año de 1824 durante su gobierno como Presidente, dio origen a la Comisión de Inmigración que tenía como finalidad acelerar los procesos de migración. La primera Ley Nacional sobre Inmigración y Colonización fue puesta en práctica en el gobierno de Nicolás Avellaneda (Ley 817 de 1876) que sirvió de marco legal para la entrada masiva de migrantes ocurrida entre 1880 y $1930^{3}$.

En las primeras décadas del siglo XX, aumentó de forma significativa no solamente la cantidad de migrantes sino la diversidad de procedencia de los mismos; lo que contribuyó a que muchos sectores sociales comenzaran a interpretar desde un punto de vista más crítico la política del Estado-nacional. Por ello, surgen las primeras restricciones en cuanto la admisión, permanencia y procedencia de los mismos.

Apoyados, además, en un escenario internacional marcado por una crisis económica mundial, la previsible conflagración bélica en Europa y los crecientes niveles de desocupación nacional, resultaron en los factores que confluyeron para que se adoptasen las primeras leyes de carácter restrictivos.

Este cambio histórico, después del período caracterizado por la "entrada masiva" de migrantes, contribuyó para que otros "imaginarios sociales" comenzaran a concebirse a respecto de los migrantes, ahora más relacionado a un "problema” o "amenaza" que como una "contribución” o "aporte” a la construcción de la nación - aunque se debe aclarar que se conservó en las elites argentinas una connotación positivada, pero acotada, a respecto de dos de sus rasgos: europea y agraria ${ }^{4}$. En este mismo contexto, la figura del migrante y del refugiado se ven superpuestos no apenas por desencuentros en cuanto la definición de quiénes serían los refugiados en los marcos legales construidos a nivel latinoamericano con el internacional, pero además, porque las élites conservadoras entendieron que los refugiados serían apenas un nuevo tipo de migrante no deseable; que podría representar una amenaza subversiva, una limitada capacidad productiva y de integración en el país debido no haber migrado de forma voluntaria. A pesar del pionerismo establecido en las normativas de América Latina sobre el tema de asilo, este estatuto era aplicado apenas para los "asilados políticos" o "exiliados" conforme fueron nombrados en este periodo, es decir, a los que pertenecían a una élite intelectual y política; lo que todavía causa cierta confusión acerca de la definición de ambos.

De acuerdo con Devoto (2009), el surgimiento de la figura del refugiado, en este contexto, marcó un cambio de positivo a negativo a respecto del "asilado político" pues, aunque la existencia de este primero subyace del ámbito del derecho internacional, se prefirió enmarcarlo dentro de una de las figuras legales existentes en el país, es decir, como un tipo de migrante más, que se rechazaba o admitía debido a razones "ideológicas" o "humanitarias". Había una cierta desconfianza 
de reconocerlos a través de la condición de refugio por su posible potencial subversivo. Además, circulaba en el escenario local una serie de expresiones denigratorias sobre los mismos, como "indeseables", "expulsados", "perseguidos", entre otros. En ese sentido, cuando el peronismo alcanzó el poder en la década de $40 \mathrm{y}$, una nueva oleada de migrantes y refugiados europeos llegaron a la Argentina, estas expresiones denigratorias ya estaban cristalizadas desde la década pasada, en contrapartida las nociones que se fortalecieron fueron las relacionadas con la idea de inmigrante-europeo-colonizador.

Por ello, entre los denominados migrantes que entraron en el país, en las primeras décadas del siglo XX, habría poblaciones civiles que estarían en situación de refugio si el marco legal de este entonces los reconociera como tal. No obstante, hoy es posible entender que la historia de los refugiados en el país dio inicio en este periodo a partir de algunos hechos, a saber: en las primeras décadas del siglo XX cuando arribaron uruguayos motivados por la guerra civil, los que escaparon por los hechos de la Primera y Segunda Guerra Mundial y la Guerra Civil Española. Con la ratificación de los marcos legales internacionales en la década de 60, ingresaron chilenos y uruguayos que huían de las dictaduras militares de sus respectivos países. Asimismo el Convenio del gobierno militar argentino con el ACNUR permitió refugiar familias indochinas y laosianas en 1979, mientras se generaba miles de presos políticos, exiliados y refugiados víctimas de la dictadura militar Argentina (ASA, COURTIS, PACCECA Y TALPONE, 2007; CICOGNA, 2009a).

$\mathrm{Al}$ no haber una normativa que reglamentaba los procedimientos para el reconocimiento del estatuto de refugiado en el país, el ACNUR era el actor incumbido de deliberar sobre el otorgamiento de refugio en el exterior. Por lo cual, los refugiados - de forma previa - arribaban a la Argentina provistos de una "tarjeta azul de identificación" que indicaba su calidad de refugiados; aunque esto no excluía que los mismos tuvieron que realizar algunos trámites de reconocimiento una vez que ingresaban al país. Asimismo, los refugiados que estaban "bajo mandato del ACNUR", cuando optaban por radicarse de forma definitiva en Argentina, tendrían que hacerlo a partir de la legislación migratoria.

Durante este contexto fue sancionada en el año de 1981 la Ley 22.439 de migración, también conocida como Ley Videla por hacer alusión al jefe de la junta militar que gobernaba la Argentina en ese contexto. La derogación de esta ley, en el año de 2004, fue recibida con gran entusiasmo por las Ong's ligadas al tema de migración y Derechos Humanos debido al fuerte contenido de cláusulas que "afectaban derechos y garantías constitucionales" como detener personas, expulsarlas sin cualquier tipo de control legal o judicial sobre la decisión. Además, otro hecho importante para subrayar, es que esta normativa planteaba la obligación de todo funcionario público y la sociedad como un todo, denunciar la presencia de migrantes irregulares 5 . 


\section{DE LA DEROGACIÓN DE LA LEY VIDELA HASTA LA ACTUAL LEY DE MIGRACIONES}

El nuevo contexto político del país, caracterizado por la transición de la dictadura a la democracia, agudizó todavía más los procesos de concentración política, económica, de desigualdad social de varios sectores de la población resultado de las políticas neoliberales, impulsadas desde los años 70 . Se observa que el fortalecimiento de estas políticas en el gobierno de Menen (1989-1999) y, sustentadas por el llamado Consenso de Washington ${ }^{6}$, reflejaron de manera directa en los altos niveles de desempleo y restricciones en cuanto al acceso a áreas sociales en el país. Estas mudanzas del modelo de Estado establecieron "procesos de descentralización administrativa" y de "desestatalización de las intervenciones sociales"; dando lugar a la emergencia de varias "formas de demanda" y diferentes "formatos de protesta" sociales, a saber: los cortes y bloqueos de rutas, calles, puentes por los primeros "agrupamientos piqueteros"; las experiencias de ocupación de tierras y la constitución de asentamientos; el desarrollo de procesos asociativos como los centros de educación popular y las "ollas populares"; la ocupación de fábricas por trabajadores ante la posibilidad de cierre ${ }^{7}$.

A partir de la lectura de este contexto histórico, Woods (2007) evidencia la manera con que la Iglesia Católica en la Argentina no fue sólo tornándose participe sino también gestora de los programas sociales direccionados a la sociedad civil en la actualidad ${ }^{8}$. En una coyuntura marcada por "la ambigüedad o indeterminación", producto de las crisis y disputas de las diferentes tendencias dentro de la iglesia, la orientación que se torna hegemónica en los años 90 es aquella que sustentó la reconstrucción de la "doctrina social" de la Iglesia, la idea de institución encargada de la "cuestión social". Fortalecida por la modalidad asistencialista, en un contexto donde las políticas sociales estaban caracterizadas por la "tercerización" de funciones de entidades de la sociedad civil, luego de la "desestatización" de las intervenciones sociales. Estos procesos, finaliza la autora, coinciden con las transformaciones de la Iglesia y el Estado en cuanto parte constitutiva de una "reorganización general del campo de la sociedad civil" (WOODS, 2007:85).

En el marco de este transcurso se establece en 1985 el Comité de Elegibilidad para los Refugiados (CEPARE), institución que tenía como principal función evaluar y resolver sobre las solicitudes de otorgamiento de estatuto de refugio en el país. En ese sentido, Cicogna (2009a) señala que la historia de los refugiados puede ser dividida en dos partes, por un lado, a partir de las poblaciones que llegaron durante la conformación del Estado-nacional y, por otro, los refugiados que empiezan a "existir" desde el punto de vista "burocrático" y "legal" en el año de 1985, con la creación de la CEPARE. Toda esta esta coyuntura política, será leída como un período de "ruptura ideológica" pues presentaba nuevos desafíos en términos de "reconstrucción constitucional" de la relación entre el Estado- 
nacional y sociedad civil. Esta ruptura, había posibilitado otros "modos" de abordar la problemática migratoria, lo que viabilizó, implementar una nueva ley ligada a la garantía de los Derechos Humanos como la actual.

Sobre este periodo, Domenech (2007) establece una lectura que permite entender, cuándo ocurrieron estos cambios al contrastar dos momentos en claves de "exclusión" y "inclusión". El primero, en los años 90, de reactualización de los discursos de la "exclusión", representado por la continuidad con las políticas migratorias de restricción. Durante la crisis socio-económica de esta década, los migrantes provenientes de los países limítrofes fueron utilizados para explicar los distintos problemas sociales y económicos que atravesaba el país. El segundo momento, en el contexto de crisis económica y política del 2001, donde se produjo un giro significativo en el discurso del Estado-nacional sobre los migrantes, reflejado en las políticas institucionales posteriores y caracterizado por un discurso "inclusivo" y de ruptura, basado en una lectura de los Derechos Humanos de los migrantes.

\section{LA “MESA" Y LA CONSTRUCCIÓN DE LA "PLATAFORMA DE PODER"}

Ahora bien, todas estas reflexiones plantearon nuevos interrogantes que me orientaron a buscar entender, de forma detenida, cómo se había establecido una plataforma de poder que logró, no solo, derogar la Ley Videla, sino que además, pretendía instituir una nueva mirada hacia la garantía de los Derechos Humanos de los migrantes. Fue cuando empecé a identificar, de manera preliminar, quiénes fueron estos actores y la "forma" en que lo hicieron. Combinada a las entrevistas, el análisis atento sobre este período relatado de forma exhaustiva por los investigadores que estuvieron involucrados con el tema de migración y refugio durante este proceso $^{9}$, posibilitaran comprender la complejidad de estas transformaciones discursivas y prácticas. En un escenario donde se desplegó una diversidad de acontecimientos, relatos e interpretaciones de los mismos, se reconstruyeron las piezas del rompecabezas que significó la conformación de lo que se conoció en un primer momento por: La mesa de organizaciones, seguida más tarde por la Comisión Asesora. Aquí comprendo que, los hechos producidos en este contexto estaban refiriéndose a una plataforma de poder, cuya heterogeneidad de las relaciones institucionales están ligados a la estructura social de este campo $y$, también, comunicaban sobre los compromisos que se asumen a partir de la representatividad, es decir, cuando una institución está incumbida de representar un grupo más amplio; fueron todos estos hechos que me llevaron a entrevistar interlocutores de Organización $D^{10}$ y a la Organización $E^{11}$ en el año de 2012.

Al comenzar a trabajar con temas ligados a la violencia policial hacia comienzos de la década 90, concretamente la que sucedía en los contextos populares se observa, desde el Organización $D$, que estos sectores aun sufrían 
las consecuencias de prácticas que se había iniciado en el periodo de la última dictadura militar en el país: detenciones arbitrarias, ilegales y muertes de "gatillo fácil" como se suele llamarlas ${ }^{12}$. En este momento se produjo un primer trabajo de identificación de los problemas vinculados al derecho de los migrantes, ya que los mismos también estaban siendo sometidos a la "discrecionalidad policial". Más adelante, la institución centra sus interrogantes en lo relativo al acceso de los derechos sociales para estos mismos sector populares y, de nuevo, se hace evidente la dificultad de acceso a los derechos relacionados a la educación, salud, trabajo y vivienda para los migrantes. De este modo, para mediado de los años 90, la Organización D decide trabajar de forma sistemática los derechos humanos de los migrantes. El trabajo inicial constituyó en acumular investigaciones, fruto de los primeros informes relacionados con los imaginarios construidos acerca de la responsabilidad de los migrantes por los problemas socio-económico del país. Conforme relata el agente esta institución: tenía que ver con disputar discursivamente porqué los migrantes en realidad eran víctimas y no responsables, ni podrían ser utilizados como chicos expiatorios, como algo que ocurre en todo lugar del planeta.

El segundo trabajo de la Organización $D$ se centró en poner a la luz la falta de garantías relacionadas a los Derechos Humanos de los migrantes. A partir de allí, se comienza identificar a los migrantes como un colectivo que requería una protección específica. En este sentido, se buscó por parte de esta institución construir un discurso favorable a los Derechos Humanos de los migrantes - he aquí que surgen las alianzas con distintas organizaciones de migrantes y refugiados como las eclesiásticas, religiosas, sindicales, entre otras - que culmina con un primer diagnóstico acerca de la principal responsabilidad material de violación de los Derechos Humanos resultado de la Ley de Migración que estaba vigente en este momento: la Ley Videla.

La realización de informes sobre la situación de los Derechos Humanos de los migrantes, articulado a litigios de casos paradigmáticos ante la justicia argentina y organismos internacionales encabezados por la Organización $D^{13}$, la producción académica sobre la problemática social de los migrantes en el país, formaron los antecedentes necesarios para la conformación de una "Mesa de Organizaciones de la Sociedad Civil para la Defensa de los Derechos de los Migrantes” en el año de 1996. La Mesa estaba compuesta por diversas instituciones de la sociedad civil, entre ellas las de carácter religioso como la Organización A y la Organización E, algunos centros de estudios relacionados al tema de migración y refugio, otros de lucha por los derechos humanos como la Organización D, entre otros. A partir de acciones colectivas como reuniones, entrevistas, presentaciones, discusiones con diputados, legislados, jueces, el objetivo era lograr construir un discurso favorable a los derechos humanos de los migrantes en todos estos ámbitos.

La Mesa logró establecer una agenda específica compartida que iba desde la derogación de la Ley Videla a la sanción de una nueva Ley de Migración. A partir de una base de principios que ellos señalaban como fundamentales ${ }^{14}$ se 
presentaron propuestas de trabajo en distintas comisiones legislativas; donde se discutió y apoyó el proyecto de ley que fue aprobado por un amplio sector político en el año de 2004. Desde este entonces, la Dirección Nacional de Migraciones (DNM) elaboró sus propuestas de reglamentación de la ley durante el periodo de 2004 hasta el 2008, todas ellas impugnadas u observadas por La Mesa. De esta manera, en el año 2008 el Poder Ejecutivo Nacional - en el ámbito del Ministerio del Interior - decide conformar una Comisión Asesora para reglamentar la Ley, ésta estaba conformada por algunas organizaciones integrantes de La Mesa ${ }^{15}$. Durante cinco meses la Comisión Asesora elaboró un documento que fue aceptado como proyecto definitivo por el Ministerio del Interior y en el año de 2010 fue aprobado por la Presidencia de la Nación.

Lo llamativo de este proceso de construcción y reglamentación de la ley, es su vinculación a un caso paradigmático ${ }^{16}$ como el llevado a cabo por la Organización $D$ en parecería con otra institución internacional de Derechos Humanos ante la Corte Interamericana. He allí, que el Estado argentino no sólo se compromete en aprobar un decreto reglamentario vinculado a ciertos estándares internacionales, pero además, prevé para ello el proyecto aprobado por la Comisión Asesora, es decir, teniendo en cuenta la participación de las organizaciones no gubernamentales. En definitiva, son todos estos relatos que ayudan a caracterizar la nueva Ley de Migraciones como un proceso que no debe ser entendido desde una deliberación construida apenas por diputados, conforme evidencia el agente de la Organización $D$, sino que además hay en cada uno de sus artículos que tanto nos interesa, cuestiones vinculadas en como la sociedad civil llevó adelante cuestiones que eran necesarias para incorporar a la ley.

\section{LA LEY NACIONAL DE REFUGIO Y LA TRAMA DE RELACIONES INSTITUCIONALES}

Se observa, durante esta misma coyuntura, la aprobación de la Ley General de Reconocimiento y Protección al Refugiado $\mathrm{N}^{\circ} 26.165$ del año 2006 y, cuando se analiza este proceso es posible entender las similitudes en relación a la actual Ley de Migración; donde incluso la mayoría de los actores que incidieron en la problemática migratoria estuvieron implicados con las discusiones sobre la aprobación Ley de Refugio, como el trabajo de citada La Mesa. Con el intuito de entender este transcurso, busqué sistematizar cuatro momentos a partir de los cuales se establecieron determinadas relaciones institucionales sobre el tema de refugio en el país.

La primera es la alianza de la Organización A y su convenio con el ACNUR. $\mathrm{Al}$ observar el momento histórico en que esta institución se involucra con el tema de migración, se debe remontar a los años 30; cuyo objetivo, en aquel entonces, era amparar las llamadas "grandes oleadas" y, en especial, los europeos que migraban luego de la Primera Guerra y Segunda Guerra Mundial. Los impactos 
sociales resultado de los procesos migratorio de este periodo, motivaron dos reconfiguraciones institucionales: la primera en la década de 50 para dar cuenta, en particular, de las necesidades de esta última migración citada $\mathrm{y}$, la segunda, producto de los nuevos cambios en los flujos migratorios que dieron lugar a partir de 1960 - básicamente los países que atravesaban período de dictaduras en el Cono Sur - lo que condujo esta institución a un convenio con el ACNUR. He aquí, que se produce el último cambio institucional y se crea en los años 70 la actual Organización A, que representaría en la actualidad uno de los principales organismos religiosos responsables por la asistencia social a los refugiados.

En segundo lugar, hay que señalar, el convenio entre la Organización D y la Organización E en el año de 2002 para la implementación de la Clínica Jurídica - que asiste los migrantes y también los refugiados que obtuvieron sus solicitudes de refugio denegadas cuando ellos lo solicitan. Fundada durante el contexto de aplicación de la Ley Videla, la Clínica tiene como objetivo garantizar un espacio de protección de los Derechos Humanos a los migrantes y refugiados, posibilitándoles el acceso a la justicia. Esta experiencia en el transcurso del tiempo fue replicado en diversas provincias del país. Los trabajos realizados en la Clínica no solo ayudaron a evidenciar las dificultades para la regularización de la situación migratoria debido al marco jurídico vigente en aquello entonces, sino también, expusieron los problemas implicados con la falta de una normativa de reconocimiento del estatuto de refugiado.

En tercer lugar, a partir de la aprobación de la Ley de Refugio, impulsada por los organismos de la sociedad civil en el año 2006; se estipularon los principios básicos relacionados con la protección de los refugiados $\mathrm{y}$, se señalaron los procedimientos necesarios para el reconocimiento de la condición de refugiado desde la armonización de los marcos legales nacionales con los internacionales. Esta ley determina la creación de la Comisión Nacional para los Refugiados (CONARE) y extingue el Comité de Elegibilidad (CEPARE). A partir de la creación de la CONARE, se amplia de forma considerable las funciones de esta institución en comparación con el órgano anterior, pues además de reconocer o denegar el estatuto de refugio, la Comisión debe buscar garantizar la protección a los derechos de los refugiados en el país (Asa et al, 2007). Se observa asimismo, que hay un reconocimiento de los agentes de organizaciones de la sociedad civil y estatal que la CONARE no es el CEPARE de este entonces, aunque todavía siguen latentes desacuerdos en relación a algunos de sus procedimientos.

Además de servir como antecedente para la Ley de Refugio, la reglamentación de la Ley de Migración también intensificó, en cuarto lugar, el trabajo de la Defensoría General de la Nación. Garantizando en su artículo 86 la intervención del Ministerio Público de la Defensa y el derecho a la asistencia jurídica en los procedimientos administrativos y judiciales que pueden llevar a la denegación de la entrada de los extranjeros, al retorno a su país o la expulsión del territorio argentino (Art. 86 Ley de Migración 25.871 de 2010). Para entender el motivo del protagonismo de esta institución en la actualidad, es necesario entender 
cuándo y cómo esta institución se involucró con el tema. El Ministerio Público de la Defensa, institución de la cual subyace la Defensoría General de la Nación, fue creada con el apoyo de diversos organismos de Derechos Humanos. Se instituye como un órgano independiente del resto de los poderes del Estado-nacional, con autonomía funcional y autarquía financiera, debido la reforma constitucional del año 1994 (art. 120 Constitución Nacional). De este modo, es un organismo considerado - desde su perspectiva - como una institución caracterizada por conformar un: extrapoder.

El Ministerio Público de la Defensa, está encargado de asegurar la asistencia y defensa judicial de las personas, servicio este que es brindado por los defensores públicos, tutores y curadores públicos. El Ministerio Público de la Nación además de ser un organismo previsto en el texto constitucional, es bicéfalo, eso significa que está compuesto de dos estructuras que son entendidas como autónomas e independientes entre sí: el Ministerio Público Fiscal y el Ministerio Público de la Defensa. Es importante señalar que anterior a la reforma constitucional, los defensores públicos estaban dispuestos dentro de la estructura del Poder Judicial y dependían funcionalmente de la Corte Suprema de Justicia de la Nación. He aquí, su explicación por operar en la actualidad según un organismo extrapoder ${ }^{17}$.

A partir de la llegada de los niños, niñas y adolescentes (NNA) no acompañados o separados de sus familias que solicitan refugio, la Defensoría amplía su campo de actuación y, en el año 2007, crea la Comisión de Asistencia legal y Protección del Refugiado, que se incumbe de la tutela de los chicos. Luego de comenzar a trabajar con esta temática, la Defensoría resignifica la función del Tutor Público al no restringir su función en asistir a los NNA, sino que, en varios ámbitos de sus vidas. Asimismo, en el 2008 la Defensoría estableció la Comisión del Migrante, cuyo objetivo es garantizar la defensa y protección de los derechos de los migrantes, sobre todo en los casos en que esté en curso el procedimiento de expulsión de extranjeros judicializados y detenidos. Para el año de 2011, la Comisión de Asistencia legal y Protección del Refugiado extiende la asistencia legal - no la económica - a los adultos solicitantes de estatuto de refugiado debido a la reglamentación de la nueva Ley de Migración en el 2010.

Por eso, la importancia para determinados sectores de luchar por la reglamentación de la ley pues ese proceso identifica, con más detalles, los principios estipulados en la misma al señalar cuales actores estarán implicados en su ejecución, en ese sentido, le da vigor práctico. Además, la reglamentación de la Ley de Migración sienta un antecedente para la Ley de Refugio, en que se estima pasará por un proceso similar: una Comisión Asesora integrada por la miembros de sociedad civil, agentes del Ministerio Público de la Defensa - papel que la Organización D desempeñó en la actual Ley de Migración - que estarían incumbidos de analizar el proyecto de reglamentación.

Al observar el proceso de producción, aprobación y reglamentación de la Ley de Migración y de Refugio, se logra entender el papel de las relaciones 
institucionales en este campo y posibilita poner de manifiesto "el poder estructural" ${ }^{18}$ que moviliza y despliega de estas relaciones, las demandas percibidas, los conflictos generados, las diferentes acciones producidas. Aquí se percibe que un hecho disparador, como representó uno de los casos paradigmáticos puede ayudar a reordenar todo un campo. No obstante, para que esto ocurriera debió ser necesario establecerse una plataforma de poder en un contexto político local que reconoció la reorganización de sus ideas y prácticas - acá hago referencia al papel de la Corte Interamericana en lo relativo a comprometer el Estado-nacional en aprobar el decreto reglamentario producido por la Comisión Asesora y la decisión del Estado argentino en aceptar esta disposición.

\section{EL "PESO DE LA TRADICIÓN" VERSUS EL "DERECHO DE MIGRAR}

Al reamar esta telaraña, se comprende que las acciones, las prácticas y las representaciones encauzadas por este conjunto de actores comunican tanto sobre los procesos de configuración institucional, como también la manera en que los migrantes y refugiados son percibidos. Desde allí se puede evidenciar "la dinámica de las estructuras", las relaciones que vinculan, interactúan, pugnan dentro de este campo, que puede ser accionado a partir de un único litigio paradigmático o desde una solicitud de reconocimiento del estatuto de refugiado. Ésta última, no es apenas una petición solitaria, una acción individual, ese mosaico de procedimientos administrativos puede volver a armarse a través de cada narrativa de refugio, paralelo a ella está anclado todo el peso de la "tradición y la variabilidad", características de las relaciones de poder, conforme se evidenció durante el largo de este trabajo.

En ese sentido, cuando Caggiono (2011) evidencia que, a pesar de la reglamentación de este marco normativo novedoso que se tornó la nueva ley de migración argentina, el autor observa que existe una continuidad de los problemas demandados por parte de los migrantes en la actualidad y, que incluso, siguen siendo similares a los relatados en los años 90 por las organizaciones de la sociedad civil. A partir de su investigación comprende que los protagonistas que impulsaron la nueva Ley de Migración, no fueron un conjunto homogéneo de instituciones de la sociedad civil, sino más bien, habría que diferenciarlos en organizaciones para los migrantes y de los migrantes ${ }^{19}$. Su hipótesis es que el protagonismo establecido por las organizaciones para y no de los migrantes puede ayudar a entender la continuidad y similitud de los reclamos a pesar de las modificaciones que impulsaron esta ley. Esta lectura, entretanto, me direcciona a otros interrogantes, en especial, a dos puntos de análisis; aunque estoy de acuerdo con el autor que se debe reconocer la heterogeneidad de los actores implicados en la construcción de este nuevo marco legal. Antes de estos análisis es necesario subrayar la dificultoso que es para los migrantes y refugiados percibirse como "sujetos de derecho"; hecho que pude observar durante el trabajo de campo con 
los solicitante de refugio señalado en la introducción, ya que aun cuando ellos se nuclean en organizaciones y formulan demandas, éstas son mediadas por un grupo más amplio de instituciones.

Ahora bien, la primera instancia de análisis es la reflexión sobre las relaciones de poder en este campo; tomando como ejemplo el papel del Organización D en La Mesa - institución que representó un amplio sector de organizaciones de sociedad civil en la reglamentación de la nueva Ley de Migración - en el sentido de impugnar u observar las propuestas de la DNM. Refuerza y sigue legitimando el poder construido por esta entidad, que está ligado al rol de la misma en la historia del país, pero también, de este conjunto de otras instituciones en percibir lo que podría significar la impugnación por la Organización D ante las propuestas de la DNM. Hecho que motivó continuos replanteos hasta que se decidió convocar esta última institución para conformar la Comisión Asesora - y fue cuando se consensuó la reglamentación de esta nueva ley. Además, se debe señalar el énfasis de esta última institución en sus casos paradigmáticos que parece construir los antecedentes necesarios y que pueden operar como símbolos de poder ante quienes se está negociando. Otro acontecimiento que se debe volver a hacer hincapié es referente al protagonismo de las instituciones religiosas que también está ligado a la "reorganización general del campo de la sociedad civil" conforme señalado por Woods (2009). En ese sentido, las relaciones construidas en este campo, que nuclearon a estos actores que posibilitaron derogar la Ley Videla, parecen haber ayudado a percibir quiénes tendrían el poder requerido para hacerlo.

El motivo de las tensiones, parece estar menos interpelado por la "forma" en que fue consensuada esta ley, y ya entrando en la segunda instancia de análisis, más ligado a la dificultad de ponerla en práctica, resultado no sólo del "imaginario social" que se produjo acerca del migrante a lo largo del tiempo, pero también, debido a las acciones producidas a partir de las normativas jurídicas establecidas en contextos políticos que las legitimaron. Incluso, estas diferencias que se interponen entre la ley y la práctica son las que también permiten establecer estos espacios de conflictos, rupturas y negociaciones Como ya señalaba Malinowski en Crimen y costumbre en la sociedad salvaje en 1926: "el derecho es apenas un aspecto de la vida", donde no hay una obediencia y ejecución mecánica del mismo, por ello, hay que buscar los sentidos producidos a partir de las normativas en cada sociedad.

En este caso, se observa que hubo una construcción histórica de la figura del migrante caracterizado en su inicio como "aporte", después como "problema" o "amenaza" en el interior de la sociedad. Por eso, la importancia para ciertos grupos dominantes, en cada coyuntura histórica, construir los discursos funcionales que legitimara sus perspectivas. Si es añadido a este imaginario su condición afro, se puede pensar acá en un proceso de doble "extranjerización" ${ }^{20}$, es decir, de exclusión al interior de la sociedad, en donde ser extranjero, el "el otro", lo de afuera también está marcado de forma implícita en los cuerpos, en los rasgos físicos. He aquí, 
que el "mito de la desaparición del negro en el país", que hace parte del mito de origen de la nación argentina ${ }^{21}$ - que permitió desde el inicio que la población fuera caracterizara como blanca y europea - opera desde un doble sentido pues, seguir afirmando sobre la extranjería del afro, en la actualidad, significa mantener los mitos fundacionales de la nación intactos. En relación a los refugiados, se debe recordar que esta figura, si bien, parece representar más asombro, debido a la falta de discernimiento de ¿quiénes son? y ¿qué hacen acá?, estuvo durante un largo tiempo delimitado desde un lugar confuso, contradictorio, aun dentro de las normativas. Ligado en principio a los asilados políticos, luego a una posible "amenaza subversiva" que podrían ser, además, improductiva, en un contexto histórico que operaba la "reserva geográfica".

A respecto de las normativas jurídicas, cuando se analizaron los años 80 y 90 , se pudo observar que estos períodos fueron marcados por la puesta en práctica de una ley que validó este imaginario social del extranjero como un "problema social", lo que posibilitó no sólo expulsar a los migrantes indeseados sin la posibilidad de defenderse por la vía judicial, más también, previa la obligatoriedad de todo funcionario público y de la sociedad denunciar la presencia de migrantes en situación irregular. Sobre los refugiados en este contexto, se puede señalar una ausencia no apenas de normativas, pero de una estructura institucional que apenas había sido creada para reconocerlos. Es acá que se comienzan a combinar algunas respuestas para el abismo entre las leyes y sus prácticas, este es un campo nuevo de disputas, conflictos y estructuración todavía. En ese sentido, diversas organizaciones de la sociedad civil, estatales e investigadores dispusieron, desde finales del año de 2010, un grupo de trabajo para discutir las estrategias para resolver las brechas jurídicas presentes en la nueva Ley de Migración, en especial, regularizar la situación migratoria de los migrantes senegaleses ${ }^{22}$.

Es importante entender que las leyes pueden transformarse, pero la tradición ligada a un habitus llevado a cabo por varias décadas y valido por la construcción de un imaginario social, no apenas, en los espacios estatales es una tarea compleja de reestructurar, ya que se estaría hablando de la producción de nuevas prácticas capaces de reorganizar todo este campo y que contrasten con el peso histórico de una tradición que fue legitimada al largo del tiempo por estos dispositivos. Más desafiante aun, cuando estos habitus son funcionales a la definición actual de la ciudadanía, que todavía sigue cumpliendo un rol fundamental para delimitar los de "afuera", los que "viven prestado," los que no pueden acceder a ciertos derechos políticos, los que deben "probar su drama". Conforme señala Penchaszadeh (2012), no se puede dejar de negar que la exclusión de los extranjeros, también establezca una función "productiva" en el interior de la sociedad que lo acoge, un fundamento sobre el cual se puede establecer una frontera tranquilizadora entre "nosotros" y los "otros".

Asimismo, es importante percibir que los agentes de las organizaciones de la sociedad civil cuando produjeron mecanismos de acción para contraponer este imaginario y construir una nueva lectura sobrelos migrantes que pudiera comenzar 
a superar estos obstáculos, eligieron empezar por el marco jurídico. Desde allí encontraran las herramientas necesarias, que entendieron como legítimas, a partir de la cual podrían seguir haciendo sus reclamos. La incorporación del "derecho de migrar" parece haber sido percibida como una garantía que pretende resignificar el imaginario social del migrante en cuanto: sujeto de derecho; que tendría respaldado en un plano normativo el derecho de decidir migrar.

El motivo de centrar los esfuerzos en cambiar el "cuerpo de leyes", me atrevo a señalar, es por este haber representado el principal dispositivo evocado por los agentes institucionales para sustentar prácticas cotidianas de "autoridad" para accionar y resolver de manera divergente sobre los ingresos y permanencias, que si no bastara fue producido en el contexto que se objetivaba superar, es decir, la última dictadura militar. Esta simbolizaba la primera herramienta que decidieron comenzar a luchar para transformar, desde allí comprendieron que podría establecer el poder necesario para provocar cambios que irían más allá de las normativas. No obstante, este desafío está en permanente tensión con el "peso de la tradición" que cuando permitió la entrada masiva de migrantes, priorizó sobretodo poblaciones provenientes de Europa, lo que contrasta con la realidad cotidiana, cuya decisión de quiénes deben merecer hacer parte del Estadonacional puede poner en suspenso la idea fundacional de homogeneidad de la nación argentina ${ }^{23}$.

Lo interesante aquí es que, por un lado, la reglamentación de la Ley de Migración, evidenció el poder de instituciones no gubernamentales para establecer espacios de negociación con los actores estatales, por otro, también aumentó el poder de estos últimos organismos, como la Defensoría General de la Nación. Los procesos de objeción del reconocimiento de estatuto de refugiado anterior al año del 2011 eran, en mayor parte, formulados por los actores de organizaciones no gubernamentales desde las ya mencionadas Clínicas Jurídicas - con excepción de las objeciones de los NNA que eran formuladas por la Defensoría desde el 2007. A partir de la reglamentación de la nueva Ley de Migración aumentó de forma contundente el rol de esta última institución, lo que puede influenciar en la reconstrucción de una lectura de un Estado más actuante. Acá me limito en evidenciar que estos hechos también pueden estar ligados a la reorganización del propio Estado que busca recuperar su arena de actuación en relación a los años 90, cuando organizaciones de la sociedad civil asumieron un rol protagónico y el Estado optó en comprimirse a un nivel mínimo de provisión de bienes públicos influenciados por las recomendaciones del Consenso de Washington.

Por lo tanto, demostrar todos los actores imbricados en la trama, posibilitó evidenciar las relaciones de fuerzas establecidas para poder luchar en este campo. Desde este lugar, se permite revelar las redes construidas, cómo los actores se posicionaran y que objetos eligieran y confiriéndoles uso diferencial de poder - pienso acá en los casos paradigmáticos. En ese sentido, analizar apenas la aplicación de una ley, dejaría afuera todos estos otros aspectos del derecho que consiste en "complicados arreglos", "negociaciones" que no apenas buscan 
hacer que las personas los cumplan, sino que, operan como un hecho social cuyas normativas pueden ser resignificadas.

\section{CONSIDERACIONES FINALES}

Una combinación de hechos parecen haber sido necesarias para el cambio de la ley de migración y la aprobación de la normativa de refugio, a saber: el establecimiento de una plataforma de poder que actuó a partir de las demandas que surgían - resultado de las arbitrariedades producidas por una ley anterior; el papel de la Corte Interamericana de entender y legitimar el proceso propio que ya estaba en curso en país - como el proyecto formulado por la Comisión Asesora para reglamentar la nueva ley de migración en base a los estándares internacionales - ; el contexto político favorable a estos cambios. Aquí, se tornó clave las organizaciones de la sociedad civil mostraren que las prácticas arbitrarias ligadas a problemática, fueron construidas en gobiernos que vulneraran de manera sucesiva los Derechos Humanos no sólo de este colectivo y, del cual, este actual gobierno busca superar: la última dictadura militar.

Lo curioso de estos procesos, de "controversias y luchas", es que también evidencian en qué medida las formas y lenguajes de la protesta o resistencia adoptan, de alguna manera, las formas y leguajes de la dominación para ser escuchados y registrados: "se reconoce y se dirige al poder aun cuando si está protestado contra él” (ROSBERRY, 2007:131). Hay que estar atento a los "marcos discursivos comunes", que son productos de la capacidad del orden dominante de establecer procedimientos legítimos, prescritos para expresar tanto aceptación como descontento. Se puede añadir acá el esfuerzo desplegado por las instituciones no gubernamentales de cambiar el dispositivo de poder que representaba para ellos el mayor obstáculo en la construcción de "sujetos de derechos": el marco normativo, es decir, el mismo dispositivo que antes era evocado para poner en marcha prácticas arbitrarias, hoy es utilizado como una herramienta de garantía de los derechos que los migrantes.

De este modo, la definición de Estado nacional de Rosberry (2007) parece dar cuenta de estas complejidades, cuando rescatando el concepto de hegemonía de Antonio Gramsci, entiende que más que un consenso, se debe entenderlo en clave de lucha. Reconoce que, si bien, el Estado posee el poder de nombrar, de dibujar e imprimir mapas, denominaciones reconocidas por él mismo, sus miembros pueden reconocer estos derechos y también decidir no usarlos, las luchas justamente tienen a ver con estos procesos. Es necesario concebir este proceso hegemónico y marco discursivo común como "proyectos del Estado" antes que logros; desde allí se puede comprender los modos por los cuales estos marcos discursivos se rompen, se desconocen y se negocian. 


\section{NOTAS}

1 Ver: LUIZ DA SILVA (2013).

2 Se esclarece que se utilizará en el texto las dobles comillas (“”) para los conceptos teóricos y términos sin traducción y las cursivas para evidenciar los términos y expresiones literales empleadas por los interlocutores reconstruidas a partir de las notas de campo.

3 Esta política de Estado priorizó poblar territorios pampeanos despoblados por sucesivas expediciones militares que doblegaron, dispersaron o aniquilaron los pueblos indígenas que habitan estos territorios. Ver: Halperin Donghi (1976); Devoto (2009); Pacecca y Courtis, 2008; entre otros).

4 Para ampliar información ver Devoto (2009).

5 Para más detalles ver: Ceriani y Morales (2011).

$6 \mathrm{El} \mathrm{"Consenso} \mathrm{de} \mathrm{Washington",} \mathrm{como} \mathrm{se} \mathrm{tornó} \mathrm{conocido,} \mathrm{es} \mathrm{un} \mathrm{listado} \mathrm{de} \mathrm{recomendaciones} \mathrm{de}$ políticas económicas para los Estados nacionales que fueron formuladas por diversos organismos financieros domiciliados en Washington. El conjunto de estas premisas influyó de manera decisiva en las reformas estructurales de los gobiernos latinoamericanos. La idea general de las recomendaciones del "Consenso" estaban ligadas a la promoción de la economía neoliberal de mercado a partir del levantamiento de los mecanismos de intervención estatal y que se convirtieron en el núcleo estratégico de las "nuevas democracias" en este continente. Asimismo, según estas premisas, el papel del Estado debería comprimirse a un nivel mínimo de provisión de bienes públicos en nombre de la eficacia económica y el libre mercado (Para ampliar: Vilas, 2000).

7 Ver: Villarreal (1985); Auyero (2002); Fernandez Alvarez (2006); Quirós (2006); entre otros.

8 Para ello, la autora analiza cómo la Iglesia fue posicionándose al largo del tiempo en su relación con el Estado y la sociedad civil. Para ampliar debate ver: Woods (2007).

9 Para ampliar ver: Giustiniani (2004); Novick (2005); Jelin (2006); Domenech (2007); Caggiano (2011); Ceriani y Morales (2011); Cels (2012).

10 Organización $D$ es una institución laica de la sociedad civil, creada durante los años 70 con la finalidad de luchar por la defensa de los Derechos Humanos.

11 Organización E fue establecida en los anõs 70, con el apoyo de organismos religiosos internacional, junto con otras organizaciones regionales se tornó una de las instituciones, a través del cual, dentro del campo religioso entendieron necesario construir estrategias prácticas para asistir, en una primera instancia, a los exiliados producto de los golpes militares sudamericanos. Más adelante, la institución amplía sus ejes de actuación con las demandas que fueron surgiendo al largo del tiempo, entre ellas, la llegada de los africanos solicitantes del estatuto de refugiado.

12 Sobre muerte de "gatillo fácil" ver: Tiscornia (1998).

13 Para dar un ejemplo de caso paradigmático, se puede citar el de una joven ciudadana peruana embarazada, cuando cerca al año 2000 falleció al tener que esperar cerca de un año por la medicación antirretroviral solicitada al Ministerio de Salud de la Nación, ya que estaba denegado el acceso al tratamiento antirretroviral a personas migrantes con VIH que no tenían la residencia en la Argentina. A partir de este caso, la Justicia Nacional sancionó al Estado a proveerle a las personas migrantes el debido tratamiento pues la atención a la salud no debe estar condicionada a la situación migratoria de las personas.

14 Los cuatro principios a saber: el control administrativo y judicial de la actividad de la DNM, reforma de los procedimientos de expulsión y detención, reconocimiento de los Derechos Humanos de los migrantes y sus familias así como, igualdad y no discriminación en el acceso a los derechos sociales. 
15 En la Comisión Asesora, la Organización D representó las Ong's, también integraban la Comisión algunos centros de estudios y organismos internacionales como el ACNUR.

16 El caso que me refiero es de los años 90 , cuando un hombre de nacionalidad uruguaya y ya habiendo vivido 24 años en el país, tuvo emitida su orden de expulsión sin posibilidades de defenderse por la vía judicial, lo que condujo a un largo fallo histórico conducido por Organización $D$ y en conjunto con otra institución internacional ante la Corte Interamericana. Este hecho, no apenas, hizo con que el Estado tuviera que "rendir cuenta" sobre su expulsión, pero lo más importante, se tornó el motor que impulsó la construcción de la nueva Ley de Migración y su posterior reglamentación. Acá, el Estado argentino se compromete en adoptar todas las medidas necesarias para garantizar el respeto de los estándares internacionales en las normativas internas. En al año de 2005, tras un acuerdo provisorio ante la Corte Interamericana, la DNM levanta la prohibición a este señor de reingresar en la Argentina.

17 Entiendo que la característica de extrapoder señalada por este organismo ameritaría, por sí solo, un análisis etnográfico denso.

18 Hago referencia a la conceptualización de Wolf (2001:20-32) que entiende el "poder estructural" aquél se manifiesta en las relaciones y, que no opera apenas dentro de los escenarios y los campos, pero además, organiza y dirige los mismos. Asimismo, el poder estructural implica una ideología que "asigna distinciones entre las personas".

19 Las organizaciones para los migrantes serían las que sin estar integradas o haber sido impulsadas por migrantes, toman los derechos de los mismos como una de sus "áreas de acción", estas fueron las que asumieron el rol protagónico en este campo. Las organizaciones de los migrantes, serían las conformadas por los/as propios migrantes y trabajan en la promoción o protección de sus derechos y estuvieron de forma esporádica en La Mesa. (CAGGIANO, 2011:11-12).

20 Sobre el proceso de "extranjerización" de los extranjeros ver Penchaszadeh (2012). En su artículo, la autora señala como la ciudadanía puede establecer una dimensión excluyente central que muchas veces opera para determinar el ser ciudadano o extranjero. Estableciendo con ello un adentro y un afuera fundamental pues, esta posibilidad también ayuda a "marcar y delimitar un campo para la acción política y jurídica de los Estados.

21 Geler (2007:116).

22 Se eligió este grupo debido a los grandes obstáculos que imposibilitaban la regularización migratoria de las personas provenientes del continente africano, cuando estos justifican migrar a la Argentina motivados por trabajo. Lo que llevó a un recién acuerdo gestionado en el inicio de año de 2013 para lograr la facilitación de la radicación de este colectivo. Los senegaleses en la actualidad representan el mayor contingente de personas procedentes de África con irregularidades en cuanto a su situación migratoria.

23 En ese sentido, Maffia y Mateo (2012) evidencia que la actual visibilidad hacia los africanos subsaharianos en la Argentina también ayudar a evidenciar otro colectivo cuya presencia fue negada sistemáticamente en el país: los afroargentinos.

\section{Referencial Bibliográfıco}

ASA, P., COURTIS, C., PACCECA, M. I., Y TALPONE, G. (2007). La población refugiada. En: Susana Torrado (Ed.). Población y bienestar en la Argentina del primero al segundo centenario. Una historia social del siglo XX. (pp. 637-663) Buenos Aires: EDHASA.

AUYERO, J. (2002). Los cambios en el repertorio de la protesta social en la Argentina. Desarrollo Económico, 42 (166), 187-210. 
CAGGIANO, S. (2011) Migrantes y luchas por derechos: Posibilidades y limitaciones de la articulación entre organizaciones En: IX Congreso de la Red de Migración y Desarrollo; Quito, FLACSO.

CELS (2012). Derechos humanos en Argentina: Informe 2012. Buenos Aires: Siglo Veintiuno Editores.

CERIANI, C. P. Y MORALES, D. (2011) Avances y asignaturas pendientes en la consolidación de una política migratoria basada en los Derechos Humanos. Buenos Aires: FIDH-Federación Internacional de Derechos Humanos y CELS-Centro de Estudios Legales.

CICOGNA M. P. (2009a). Breve Historia de los Refugiados en Argentina durante el Siglo XX. HAOL, 18, 51-63.

DOMENECH. E. (2007). "La agenda política sobre migraciones en América del sur: el caso de la Argentina”, En: Revue européenne des migrations internationales, 23 (1)

DEVOTO, F. (2009). Historia de la inmigración en la Argentina. Buenos Aires: Sudamericana.

FERNANDEZ ALVAREZ, MI (2007). De la recuperación como acción a la recuperación como proceso: prácticas de movilización social y acciones estatales en torno a las recuperaciones de fábricas. Revista Cuadernos de Antropología Social, 25, 89-110.

GELER, L. (2007) ¡"Pobres negros”! Algunos apuntes sobre la desaparición de los negros argentinos. En: JORDÁN, P. G. Estado, región y poder local en América Latina, siglos XIX y XX. (pp. 115-153). Barcelona: Publicacions i Edicions de la Universitat de Barcelona.

GIUSTINIANI, R. (2004). Migración: un derecho humano. Buenos Aires: Prometeo.

GUBER, R. (2001). La etnografía: método, campo y reflexividad. (Vol. 11). Bogotá: Editorial Norma.

JELIN, E. (2006). Migraciones y derechos: instituciones y prácticas sociales en la construcción de la igualdad y la diferencia. En: A. GRIMSON, Y E. JELIN (comp.) Migraciones regionales hacia la Argentina. Diferencia, desigualdad y derechos. (pp. 4768).Buenos Aires: Prometeo

HALPERIN DONGHI, T. (1976). ¿Para qué la inmigración? Ideología y política inmigratoria y aceleración del proceso modernizador: el caso argentino (1810-1914). Jahrbuch für Geschichte Lateinamerikas-Anuario de Historia de América Latina (JbLA), 13, 437-489.

LUIZ DA SILVA, T. J. (2013) ¿Por qué te pintaste así? El reconocimiento del estatuto de refugio a los africanos residentes en Argentina. Argentina. Córdoba: Anais da X Reunião de Antropologia do MERCOSUL.

MAFFIA, M. Y MATEO, L. M. (2012). Africanos y Afrodescendientes en la Argentina. Presentes, Visibles y Luchando por sus derechos. Revista Voces, 3, (21). 
MIRANDA, A. P. M. (2005). Antropologia, Estado Moderno e Poder: perspectivas e desafios de um campo em construção. Revista Avá, 7, 1-27.

NOVICK, S. (2005). Evolución reciente de la política Migratoria Argentina. En: XXV internacional Population Conference, Tours, Francia.

PACECCA, M. I. COURTIS, C. (2008). Inmigración contemporánea en Argentina: dinámicas y políticas. Santiago de Chile: Centro Latinoamericano y Caribeño de Demografía (CELADE) - División de Población de la CEPAL.

PENCHASZADEH, A.P. (2012). Migraciones y derechos políticos. Un debate actual. Revista Voces, 3 (21) 30-35.

QUIRÓS, J. (2006). Cruzando la Sarmiento: Una etnografía sobre piqueteros en la trama social del sur del Gran Buenos Aires. Buenos Aires: Antropofagia.

ROSBERRY, W. (2007). Hegemonía y el lenguaje de la controversia. En: LAGOS, M. L. Y CALLA, P. (Comp.) Antropología del Estado. Dominación y prácticas contestatarias en América Latina. (pp. 117-139). La Paz: Cuadernos de Futuro № 23 - INDH/PNUD.

TISCORNIA, S. (1998). Violencia policial. De las prácticas rutinarias a los hechos extraordinarios. En: IZAGUIRRE, I. (Comp.). (pp.125-146). Violencia social y derechos humanos. Buenos Aires: Eudeba.

VILAS, C. M. (2000). Más allá del "Consenso de Washington”? Un enfoque desde la política de algunas propuestas del Banco Mundial sobre reforma institucional. Revista del CLAD Reforma y Democracia, 18, 25-76.

VILLARREAL, J. (1985). Los hilos sociales del poder. Buenos Aires: Siglo XXI.

WOLF, E. (2001). Figurar el poder: ideologías de dominación y crisis. D.F. México: Centro de Investigaciones y Estudios Superior en Antropología Social-CIESAS.

WOODS, M. (2007). Modalidades y límites de la intervención de la Iglesia Católica en conflictos sociales territoriales. De la mediación a la confrontación en la diócesis de Quilmes. En: CRAVINO, M. C., Y CALELLO, T. (Org.) Resistiendo en los barrios: acción colectiva y movimientos sociales en el Área Metropolitana de Buenos Aires. (pp.77-100). Universidad Nacional de General Sarmiento. 


\section{Resumen}

El presente artículo es fruto de una investigación etnográfica realizada en Argentina acerca de las narrativas de los africanos solicitantes del estatuto de refugiado, bien como, de los actores instituciones implicados con el tema. Desde allí, surge la necesidad de comprender el trasfundo de las diferencias que se interponían entre las leyes y sus prácticas cotidianas. Buscar estas respuestas condujo a una larga inmersión historiográfica que evidencio como los "imaginarios sociales" construidos al largo del tiempo, a respecto de los migrantes y refugiados, todavía juegan un papel significativo a la hora de hacer inteligible la principal consigna alzada por el nuevo el marco jurídico que reconoce el "derecho de migrar".

Palabras-clave: Refugiados. Migrantes. Normativas jurídicas. Imaginarios sociales. 


\title{
A NOVA POLÍTICA MIGRATÓRIA NA ARGENTINA: A TENSÃO ENTRE O “DIREITO DE MIGRAR" E OS "IMAGINÁRIOS SOCIAIS" HISTÓRICAMENTE CONSTRUIDOS
}

\begin{abstract}
Resumo
Este artigo é o resultado de uma pesquisa etnográfica realizada na Argentina, em narrativas de requerentes africanos do Estatuto de Refugiados, bem como, de instituições-atores envolvidas com a questão. Disso então, parte a necessidade de compreensão do pano de fundo das diferenças que estavam entre as leis e suas práticas diárias. A busca destas respostas findou por conduzir a uma profunda imersão historiográfica, que evidencio como "Imaginário social" construído ao longo do tempo, em relação a migrantes e refugiados, que continua a desempenhar um papel significativo no sentido de tornar inteligível o principal slogan levantado pelo novo marco jurídico que reconhece o "direito a migrar".
\end{abstract}

Palavras-chave: Refugiados. Migrantes. Normas jurídicas. Imaginarios sociais. 


\title{
THE NEW MIGRATORY POLICY IN ARGENTINA: THE TENSION BETWEEN THE "RIGHT TO MIGRATE" AND THE "SOCIAL IMAGINARIES" HISTORICALLY BUILT
}

\begin{abstract}
This article is the result of an ethnographic research made in Argentina, in narratives of african applicants of the Statute of Refugees, as of institutions-actors involved with the question. Therefore so, comes up the necessity of understanting the background of the differences wich were between the laws and its daily practices. The search of its answers ended to conduct to a deep historiographical immersion, that I discover as a "Social Imaginary" built over the time, regarding to migrants and refugees, that continue to develop a significative role in the sense of turn intelligible the main slogan arised by the new legal framework that recognizes the "right to migrate".
\end{abstract}

Keywords: Refugees. Migrants. Legal norms. Social Imaginaries.

Recebido em 24 de agosto de 2017 Aprovado em 30 de maio de 2018 